\title{
Clinico-demographic and treatment seeking profile of children below 15 years attending the anti-rabies clinic
}

Background: Rabies being $100 \%$ fatal disease, every individual is vulnerable to animal bite irrespective of age, sex and socio-economic status. Children are at greater risk. Though most of the bites are by pet animal and provoked, they are more severe, usually on proximal part of the body including face, neck and scalp and thus lifethreatening. Materials and Methods: A cross-sectional hospital based study in the anti-rabies vaccination (ARV) clinic from November to April 2013. Every new child below 15 years attending the out-patient department was interviewed along with his parents for demographic data, details of animal bite and treatment received and also myths following animal bite after taking an informed consent using a pre-designed proforma. The results were analyzed by proportion and percentages. Results: Prevalence of animal bite in children was found to be $32.98 \%$. It was more in the age group of $5-10$ years and rural children. Nearly $23.96 \%$ of children were having lacerated wound and $11.75 \%$ were having injury on head and face. About $31.12 \%$ of the children reported late by $24 \mathrm{~h}$. Local cleaning of wound was not satisfactory in $66.82 \%$ of the children. ARV schedule was not completed by $8.99 \%$ of the children while anti-rabies serum was not received by $86.16 \%$ of children. Myths regarding restrictions of milk and rice were prevalent in $94.56 \%$ population. After counseling also $44.67 \%$ were reluctant to the advice. Conclusion: About one-third of cases being related to children, prevention and control strategies are needed to reduce it.

Key words: Animal bite, anti-rabies clinic, children, immunoglobulins, provoked bites, rabies

Rupali A. Patle, Gautam M. Khakse

Department of Community Medicine, Shri Vasantrao Naik Government Medical College,

Yavatmal, Maharashtra, India

Address for the Correspondence:

Dr. Rupali A. Patle, Plot No. 6-A,

Old Subhedar Lay Out, Sharda Chowk, Nagpur - 440 024, Maharashtra, India.

E-mail:drrupali_patle@rediffmail.com

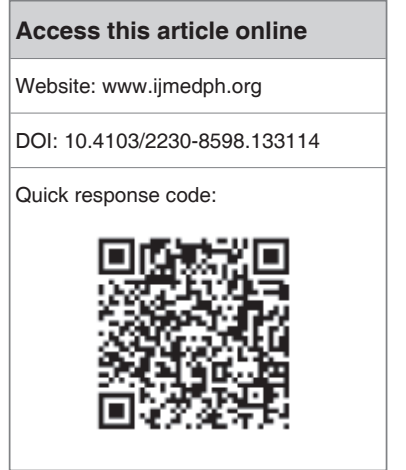

\section{INTRODUCTION}

Rabies is a zoonotic disease caused by the bite of infected animal carrying virus in their saliva. It is 100\% fatal disease. All the persons irrespective of their age, sex and socio-economic status are susceptible. Children are at higher risk to the animal bite because of their unawareness. Though most of the bites are provoked, they are generally more severe like lacerated wounds and are usually on proximal part of the body including face, neck and scalp and thus life-threatening. Bites by pet animal are more in children than older person followed by stray dogs. Animal bite in the age group of 5-10 years is more common. Still today when treatment options in the form of vaccine, immunoglobulin are available, people as well as health care professional preferably in the peripheral hospitals have not realized its importance and thus treatment received is often not complete and satisfactory.

More myths are followed after animal bite including restriction on different food items such as milk and rice for around a month following bite and also during vaccination. This can have impact on health of the child. Treatment from quacks is still prevalent in both urban and rural area which is useless. This study was carried out to know clinico-demographic profile of animal bites in children less than 15 years and also to know myths followed after animal bite.

\section{Aims and objectives}

1. The aim of the present study is to know clinico-demographic profile of animal bites in children $>15$ years attending anti-rabies vaccination (ARV) OPD. 


\section{MATERIALS AND METHODS}

This was a cross-sectional hospital based study done in the clinic of the tertiary care hospital. The study period was for a period of 6 months from November 2012 to April 2013. Daily out-patient department (OPD) attendance at ARV clinic includes around 15-20 new cases of animal bite. Every new child below 15 years attending the OPD was interviewed along with parents or person accompanying the child, after taking informed consent from parents or accompanying person. Using predesigned proforma, they were interviewed for demographic data including age, sex, residence, details of animal bite, treatment received and also myths following animal bite. Details about treatment history included local washing, administration of tetanus toxoid, anti-rabies serum (ARS) and vaccine. Local cleaning of wound was considered satisfactory if the wound was cleaned for about $10 \mathrm{~min}$ with soap and water or antiseptic. For classifying the wounds World Health Organization classification of exposure was used. ${ }^{[1]}$

\section{RESULTS}

Of the total cases of animal bite, number of animal bite cases in children below 15 years was found to be 434 (32.98\%). It was highest in the month of January and least in the month of April but having no specific trend [Table 1].

In this study, $32.49 \%$ of the children were in the age group of $0-5$ years which is a serious issue [Table 2]. Nearly $52.53 \%$ children were bitten by the stray animal while $44.47 \%$ by pet animal. Only ten cases had reported due to wild animal bite. $23.96 \%$ of children had lacerated wounds. $44.01 \%$ of children were having bite on upper limb followed by $37.10 \%$ on lower limbs [Table 3]. When further analyzed, it was found that $51(11.75 \%)$ of the children were having bite on face and head out of which 30 (6.91\%) children were having severe lacerated wound. Head and face was a common site in children $<5$ years of age. $48.39 \%$ children were of Category II and $51.61 \%$ of Category III bites. No child was of Category I bite [Table 3]. Health seeking behavior was assessed by their time of reporting to the hospital after bite. Only $10.36 \%$ of the children had reported to the hospital in less than 1 h. $31.11 \%$ of the children had reported after 24 h out of which $16.82 \%$ had reported within 3 days and $14.29 \%$ after 3 days [Table 4]. $4(0.92 \%)$ children had reported after 15 days of animal bite.

Children under 15 years if completely immunized as per national immunization schedule, don't need post-exposure prophylaxis for animal bite. 261 (60.14\%) were completely immunized according to schedule. However, $39.86 \%$ had not completed their primary immunization. Hence, they were vaccinated in the OPD with tetanus toxoid [Table 5]. Out of 173 children who were administered with tetanus toxoid, $128(73.99 \%)$ were in the age group of $10-15$ years because they had not received dose at 10 years while $37(21.38 \%)$ were in the age group of 5-10 years because they had not received booster dose at 5 years. $8(4.63 \%)$ children were in the age group of $0-5$ years because they had not received booster dose at 18 months.

\begin{tabular}{lccc}
\multicolumn{4}{l}{$\begin{array}{l}\text { Table 1: Distribution of animal bite cases in } \\
\text { children below } \mathbf{1 5} \text { years }\end{array}$} \\
\hline Month & $\begin{array}{c}\text { Total number } \\
\text { of cases }\end{array}$ & $\begin{array}{c}\text { Number of } \\
\text { children }\end{array}$ & Percentage \\
\hline November & 151 & 43 & 28.48 \\
December & 219 & 60 & 27.40 \\
January & 248 & 93 & 37.50 \\
February & 262 & 88 & 33.58 \\
March & 238 & 88 & 36.97 \\
April & 198 & 62 & 31.31 \\
Total & 1316 & 434 & 32.98 \\
\hline
\end{tabular}

\begin{tabular}{|c|c|c|}
\hline Demographic characters & Number of children & Percentage \\
\hline \multicolumn{3}{|l|}{ Age } \\
\hline $0-5$ years & 141 & 32.49 \\
\hline $5-10$ years & 162 & 37.32 \\
\hline $10-15$ years & 131 & 30.19 \\
\hline \multicolumn{3}{|l|}{ Residence } \\
\hline Urban & 197 & 45.39 \\
\hline Rural & 237 & 54.61 \\
\hline \multicolumn{3}{|l|}{ Sex } \\
\hline Male & 220 & 50.69 \\
\hline Female & 214 & 49.31 \\
\hline
\end{tabular}

\section{Table 3: Distribution of children according to description of wounds in animal bite cases}

\begin{tabular}{lcc}
\hline Description of wounds & Number of children & Percentage \\
\hline Animal & 420 & \\
Dog & 4 & 96.78 \\
Cat & 10 & 0.92 \\
Pig & 0 & 2.30 \\
Other & & 0 \\
Status of dog & 193 & \\
Pet & 228 & 44.47 \\
Stray & 13 & 52.53 \\
Wild & & 3.00 \\
Type of wound & 109 & \\
Bite mark & 64 & 25.12 \\
Puncture wound & 157 & 14.75 \\
Abrasion & 104 & 36.17 \\
Lacerated wound & & 23.96 \\
Site of bite & 191 & \\
Upper limb & 161 & 44.01 \\
Lower limb & 51 & 37.10 \\
Head and face & 4 & 11.75 \\
Trunk & 27 & 0.92 \\
Back & & 6.22 \\
Category of wound & 0 & \\
I & 210 & 58.39 \\
II & 224 & \\
III & & \\
\hline & & \\
\hline
\end{tabular}

ARV was advised to all 434 children, but it was not completed by $8.99 \%$. Out of 39 individuals who had not completed schedule, 19 $(48.72 \%)$ individuals had not received one dose and $20(51.28 \%)$ had 
not received 2 doses. It was important that $86.16 \%$ children did not receive ARS [Table 5]. Reasons for not receiving ARS were exposure to pet dog, unwillingness to sign the consent. Unavailability of ARS in the hospital along with unwillingness of parents to purchase it because of its cost is another factor.

It was important finding that myths following animal bite cases are very prevalent in the population attending ARV clinic. 410 $(94.56 \%)$ of the parents said that it is important to avoid rice and milk after dog bite and also during vaccination. 15 (3.62\%) had applied oil and turmeric at the site of bite. Although 33 $(7.55 \%)$ had taken treatment from the traditional quack before coming to hospital. After counseling in ARV OPD about myths it was found that $55.33 \%$ of the individuals had started the routine diet to their children while $140(44.67 \%)$ were reluctant to advice. Reason given was pressure by elderly in the house and fear shown by neighborers of developing disease when these restrictions not followed.

\begin{tabular}{|c|c|c|}
\hline Time of reporting & Number of children & Percentage \\
\hline \multicolumn{3}{|l|}{ Time of reporting to hospital } \\
\hline$<1 \mathrm{~h}$ & 45 & 10.36 \\
\hline $1 \mathrm{~h}-1$ day & 254 & 58.53 \\
\hline 1 day- 3 days & 73 & 16.82 \\
\hline$>3$ days & 62 & 14.29 \\
\hline \multicolumn{3}{|l|}{$\begin{array}{l}\text { Reasons for reporting late } \\
(>1 \text { day })^{*}\end{array}$} \\
\hline Not told by child about bite & 59 & 43.71 \\
\hline $\begin{array}{l}\text { Treatment by traditional } \\
\text { quacks initially }\end{array}$ & 33 & 24.44 \\
\hline $\begin{array}{l}\text { Unawareness regarding } \\
\text { importance of early reporting } \\
\text { in bite cases }\end{array}$ & 30 & 22.22 \\
\hline Animal well and alive & 13 & 9.63 \\
\hline
\end{tabular}

$*_{135}$-reported late (>1 day)

\begin{tabular}{|c|c|c|}
\hline Treatment of wound & Number of children & Percentages \\
\hline \multicolumn{3}{|l|}{ Local cleaning } \\
\hline Satisfactory & 144 & 33.18 \\
\hline Not satisfactory & 290 & 66.82 \\
\hline \multicolumn{3}{|l|}{ Tetanus toxoid } \\
\hline $\begin{array}{l}\text { Completed primary } \\
\text { immunization as per } \\
\text { national immunization } \\
\text { schedule }\end{array}$ & 261 & 60.14 \\
\hline Tetanus toxoid given & 173 & 39.86 \\
\hline \multicolumn{3}{|l|}{$\mathrm{ARS}^{*}$} \\
\hline Yes & 31 & 13.84 \\
\hline No & 193 & 86.16 \\
\hline \multicolumn{3}{|l|}{ ARV } \\
\hline Schedule completed & 395 & 91.01 \\
\hline Schedule not completed & 39 & 8.99 \\
\hline
\end{tabular}

$* N=224$ as ARS is indicated in all Category III bites. ARS = Anti-rabies serum, $\mathrm{ARV}=$ Anti-rabies vaccination

\section{DISCUSSION}

In this study, almost one-third of the OPD patients visiting to ARV clinic were children less than 15 years. A study done by Behera et al. ${ }^{[2]}$ and Mohanty et al. ${ }^{[3]}$ showed prevalence of animal bite in Children from 0 to 14 years to be more than $33 \%$. In a study by Bedi et al. ${ }^{[4]}$ and Lai et al., ${ }^{[5]}$ half of the animal bite victims were in children $<10$ years of age.

In our study, $37.32 \%$ of the children were in the age group of $5-10$ years. Nearly $32.49 \%$ of children were less than 5 years which is a serious issue. In a study by Bajwa and Anjum ${ }^{[6]}$ showed prevalence of animal bite was same in children between 5 and 15 years but cases in the age group of 5 years were $8.6 \%$. Dog bite mostly by pet or stray dog was the most common similar to those found by Bedi et al..$^{[4]}$ and Behera et al. ${ }^{[2]}$ In our study although most common injury was abrasion, around $24 \%$ of the children suffered lacerated wounds, thus increasing the severity. However, $11.75 \%$ of children had injury on head and face. The injury on head and face was lacerated wound in most of the cases. According to study by Vinay et al. ${ }^{[7]}$ most common site of bite was lower limb followed by upper limb and head and neck.

In our study none belonged to Category I bite. This also suggests unawareness of people to report to hospital in case of licking by animal. In a study by Behera et al..$^{[2]}$ majority of cases $(95.6 \%)$ were having Category III exposure. Only 0.5\% were Category I exposure which did not require any treatment. In our study, $58.53 \%$ of the children had reported within $24 \mathrm{~h}$ of animal bite. Most common reason was delay in the revelation by child about the wound. This could also be because of unawareness of children or fear of parents. Nearly $10.36 \%$ of subjects had reported within $1 \mathrm{~h}$ of bite. Thus around $69 \%$ of the children reported within $24 \mathrm{~h}$ which is greater than in most of the studies. In a study by Behera et al., ${ }^{[2]}$ after exposure, $12.6 \%$ of the patients came to ARC within $24 \mathrm{~h}$ after exposure. $2.4 \%$ of subjects reported to the ARC after 7 days of exposure and $0.5 \%$ reported after 1 month of exposure. In a study by Khokkhar et al. ${ }^{[8]}$ found that $31.03 \%$ reported after $24 \mathrm{~h}$.

Local cleaning of wound after animal bite reduces risk by $80 \%$. But it was not satisfactory in $66.82 \%$ of the children. During national immunization schedule, five doses of DPT and 2 doses of tetanus toxoid at 10 and 16 years has to be received. However it was incomplete to date in $39.86 \%$ of children which is a serious issue. ARS is recommended for Category III wounds. But in our study, it was received by $13.84 \%$ of the children. A study by Vinay et al. ${ }^{[7]}$ found only $8.2 \%$ of the Category III patients received ARS, the reasons were almost same in both the studies, also suggests common problems in different regions. Although $91 \%$ of the children completed their ARV schedule, 9\% had not completed it. They didn't even visit the hospital after missing their schedule. They could not be followed thereafter. 
Following the religious customs after bite was found most prevalent with food. Avoidance of rice and milk (white food) was present in $95 \%$ children. In a study by Singh and Choudhary, ${ }^{[0]} 19.2 \%$ of the people followed religious customs. $7.55 \%$ of patients had visited quacks before being to the hospital.

\section{CONCLUSIONS}

About one-third of animal bite patients were children below 15 years with severe wounds, mainly on proximal part of the body, mostly bitten by stray dogs. Health seeking behavior after the bite including self-care at home, approaching to health facility and treatment at hospital was not satisfactory in most of patients. Myths are also followed after bite and during vaccination also. So there is a need to conduct IEC activities in both rural and urban areas regarding severity of animal bite in children and ways to prevent it. Furthermore information about dangers of animal bites as well as importance of immunization should be included in the school curriculum of children.

\section{ACKNOWLEDGMENT}

I express my sincere gratitude to Mr. S. R. Gawalpanchi for his immense help in editing the manuscript. I acknowledge help of my colleague Dr. Dole, Dr. Bhaisare, Dr. Waghmare, Dr. Jogdadande.

\section{REFERENCES}

1. WHO Expert Consultation on Rabies, First Report. Geneva: World Health Organization; 2005. WHO Technical Report Series, No. 931.

2. Behera TR, Satapathy DM, Tripathy RM, Sahu A. Profile of animal bite cases attending ARC. APCRI Journal 2008;IX:p. 15.

3. Mohanty M, Giri PP, Sahu M. A Study on the profile of animal bite cases attending the anti-rabies vaccination OPD in SCB Medical College and Hospital, Cuttack, Orissa. APCRI Journal 2009;X:p. 23.

4. Bedi R, Bedi DK, Tankha A, Choudhary V, Matoria RS. Profile of animal bite attending anti rabies clinic of JLN medical college and hospital Ajmer. APCRI Journal 2006; VIII:28-30.

5. Lai P, Rawat A, Sagar A, Tiwari K. Prevalence of dog-bites in Delhi: Knowledge and practices of residents regarding prevention and control of rabies. Health \& Population-Perspectives and Issues 2005;28:50-7.

6. Bajwa MA, Anjum A, Manzoor S. Dog bites; assessment of burden, determinants and public services available for their victims in district. Lahore Professional Med J 2012;19:700-9.

7. Vinay M, Mahendra BJ, Poornima S. Profile of animal bite victims and compliance to the 4 dose IDRV schedule among children attending anti rabies clinics, MIMS, Mandya. APCRI Journal 2005;XI:38-40.

8. Khokkhar A, Meena GS, Mehra M. profile of dog bite cases attending MCD dispensary at Alipur, Delhi. Indian Journal of Community Medicine 2005;28:157-9.

9. Singh US, Choudhary SK. Knowledge, attitude, behavior and practice study on dog bites and its management in the context of prevention of rabies in rural community of Gujarat. Indian Journal of Community Medicine 2005;30:81-3.

How to cite this article: Patle RA, Khakse GM. Clinico-demographic and treatment seeking profile of children below 15 years attending the anti-rabies clinic. Int J Med Public Health 2014;4:151-4.

Source of Support: Nil, Conflict of Interest: None declared. 